\section{RESEARCH ARTICLE 10.1029/2019JE006053 \\ Impact History and Regolith Evolution on the Moon: Geochemistry and Ages of Glasses from the Apollo 16 Site}

Special Section:

50 years of Apollo Science

Key Points:

- First comprehensive major element, trace element, and Arisotopic age study of Apollo 16 regolith glasses

- Argon plateau age distribution dominated by young $(<500 \mathrm{Ma})$ glasses, similar to observations at other lunar landing sites

- Ar loss by diurnal heating is probably not a major control on the age distribution but other preservation biases may be important

Correspondence to: M. D. Norman,

marc.norman@anu.edu.au

Citation:

Norman, M. D., Jourdan, F., \& Hui, S. S. M. (2019). Impact history and regolith evolution on the moon: geochemistry and ages of glasses from the Apollo 16 site. Journal of Geophysical Research: Planets, 124, 3167-3180. https://doi.org/ 10.1029/2019JE006053

Received 15 MAY 2019 Accepted 12 SEP 2019

Accepted article online 15 OCT 2019 Published online 3 DEC 2019

\author{
Marc D. Norman ${ }^{1}$ iD, Fred Jourdan ${ }^{2}$ iD, and Simeon S. M. Hui ${ }^{1}$ \\ ${ }^{1}$ Research School of Earth Sciences, The Australian National University, Canberra, Australia, ${ }^{2}$ Department of Applied \\ Geology and John de Laeter Centre, School of Earth and Planetary Sciences, Curtin University, Perth, WA, Australia
}

\begin{abstract}
Lunar impact glasses are quenched droplets of melt that carry geochemical records of their target compositions, formation ages, and time-integrated exposure in the upper layers of the lunar regolith. Here we present the first study to obtain major element, trace element, and Ar isotopic data for impact glasses from the Apollo 16 regolith sample 66031. Thirty particles were analysed with 27 of them yielding useable age information. The glasses have a wide range of major and trace element compositions, similar to that observed in lunar meteorites. Half of these glasses have compositions similar to Apollo 16 soils and are considered to be "locally derived", whereas the others represent diverse source regions and are considered to be "exotic" particles that were delivered from a considerable distance to the landing site. Almost $40 \%$ of the samples analysed for this study have formation ages younger than 500 Ma. Duplicate particles produced in single impact events contribute minimally to the age distribution, and diurnal or transient heating of the regolith does not appear to have had a significant effect on the ${ }^{40} \mathrm{Ar} /{ }^{39} \mathrm{Ar}$ ages. Rather, the ages reflect primarily the formation of these glasses by impact melting, with the distribution modified to some degree by preservation bias. As most of these glasses are likely formed by relatively small impactors, their age distribution cannot be compared directly with the crystalline lunar melt rocks to constrain the impact mass flux through time.
\end{abstract}

Plain language summary The Moon records at least 4 billion years of impact history in the inner solar system. For this study, we measured the ages and compositions of a suite of glass particles found in a sample of regolith that was collected at the Apollo 16 site. The data show that the glass particles were formed mainly by small impact events and that many of them were transported vast distances across the surface of the Moon. Their formation ages are predominantly young ( $<500 \mathrm{Ma})$, possibly because of destruction of older particles by subsequent impacts.

\section{Introduction}

Collisions between planetary bodies are an important process in their formation and subsequent evolution. Geological records provide primary, albeit imperfect constraints on the timing and nature of these processes. These records include a variety of lunar and terrestrial impact deposits (French, 1998; Grieve \& Pesonen, 1996; Jourdan, 2012; Jourdan et al., 2012; Norman, 2005; Taylor et al., 1991), size-frequency distributions of lunar and terrestrial craters (Fassett, 2016; Ivanov et al., 2002), and meteorites derived from the Moon, Mars, and asteroid parent bodies (Bogard, 2011). A unique record of impact history is provided by small particles of glass that are found in the lunar regolith. These particles are quenched droplets of melt that carry geochemical records of their target compositions, impact formation ages, and time-integrated exposure duration in the upper layers of the lunar regolith. Extracting all of this information from single grains is challenging, however, because of the small size of most lunar regolith glasses (typically $<1 \mathrm{~mm}$ diameter).

Early studies of lunar regolith glasses established compositional groups and criteria that distinguish impact from volcanic glasses (e.g., Delano, 1986; Delano \& Livi, 1981; Reid et al., 1972). In pioneering work, Culler et al. (2000) and Levine et al. (2005) obtained ${ }^{40} \mathrm{Ar} /{ }^{39} \mathrm{Ar}$ data on large numbers of individual glass particles from Apollo 14 and Apollo 12 soils, respectively, which they interpreted as reflecting the impact histories of the Earth and Moon. Subsequent studies have obtained additional data using $\mathrm{Ar}$ and/or Pb isotopes (e.g., Delano et al., 2007; Nemchin et al., 2013; Nguyen \& Zellner, 2019; Norman et al., 2012, 2014; Zellner et al., 2009a, 2009b, 2013; Zellner \& Delano, 2015), although some of these studies have yet to be formally published. 
The ages of lunar impact glasses extend from modern to >4 Ga (Huang et al., 2018; Zellner, 2017; Zellner \& Delano, 2015). A striking feature of the lunar impact glass age distribution is the abundance of young ages ( $\leq 500 \mathrm{Ma}$ ), which could suggest either an increase in recent impact activity, an over-representation of ejecta from young craters, or physico-chemical factors such as Ar loss during diurnal or transient heating of the lunar regolith (e.g., Gombosi et al., 2015; Huang et al., 2018; Mazrouei et al., 2019; Shuster \& Cassata, 2015; Zellner \& Delano, 2015). In order to evaluate these possibilities and to provide additional constraints on impact ages and source terranes of lunar regolith glasses, we measured the major and trace element geochemistry and Ar isotopic compositions of individual glass particles from regolith collected at the Apollo 16 site. The aim of this study is to contribute to an understanding of lunar bombardment and evolution of the lunar surface by constraining the ages and provenance of these glasses. This study, for the first time, presents geochronologic data for a diverse suite of Apollo 16 glasses and integrates major and trace element chemistry with ${ }^{40} \mathrm{Ar} /{ }^{39} \mathrm{Ar}$ dates and cosmogenic exposure ages for individual impact glasses. The data provide constraints on the contributions of multiple particles from single events, local versus distal impact events, and effects of regolith processes on impact glass age distributions.

\section{Samples and Methods}

Samples for this study come from a split of soil 66031 that was collected at Station 6, Apollo 16. Station 6 was on the southern traverse of the landing site, near the base of Stone Mountain. 66031 is a highly mature soil with an $\mathrm{I}_{\mathrm{S}} / \mathrm{FeO}$ value of 102, reflecting extended reworking time of the sample in the upper few $\mathrm{cm}$ of the lunar surface (Morris, 1978). The original sample was collected using a surface scoop and weighed $135 \mathrm{~g}$. To our knowledge, there have been no previous studies of glasses from 66031 although Delano et al. (2007) studied particles from companion soil sample 66041 and obtained an ${ }^{40} \mathrm{Ar} /{ }^{39} \mathrm{Ar}$ age of $3721 \pm 60$ Ma on a KREEP-rich glass shard from that soil.

One of the challenges faced by studies of lunar regolith glasses is to maximize the amount of information obtained while minimizing sample consumption. For example, it is desirable to collect major element, trace element, and isotopic data on individual particles in order to evaluate provenance and ages using progressively more destructive techniques. Levine et al. (2005) measured major element compositions of unmounted glass particles by field emission SEM prior to Ar isotopic analysis in order to screen out likely volcanic glasses based on $\mathrm{Mg} / \mathrm{Al}$ ratios and to identify intra-grain heterogeneity. In contrast, Zellner and colleagues (Zellner et al., 2009a, 2009b; Zellner \& Delano, 2015) prepared polished mounts of individual grains for quantitative measurement of major element compositions by electron microprobe and then recovered the particles for Ar isotopic analysis by dissolving the adhesive. For this study we trialled an alternative mounting technique using the conductive adhesive Leit-C Plast (LCP; Witcomb 1985). This allowed for rapid mounting and analysis of a large number of particles for major elements by electron microprobe (EMP) and trace elements by laser ablation ICPMS (LA-ICPMS). A disadvantage of this approach is that the particles were not polished, which has the potential to introduce systematic uncertainties into the EMP data, with the main effect being an under-estimation of lighter elements such as $\mathrm{Al}$ and $\mathrm{Si}$ by $\sim 2-4 \%$ relative to analysis of a polished surface. However, it also allowed relatively easy recovery of individual particles for ${ }^{40} \mathrm{Ar} /$ ${ }^{39} \mathrm{Ar}$ analysis.

Major element compositions of 272 glassy particles were determined by electron microprobe and trace element abundances were measured by laser ablation ICPMS. Based on their sizes, $\mathrm{K}_{2} \mathrm{O}$ contents, and the other major and trace element data, 30 particles were selected for ${ }^{40} \mathrm{Ar} /{ }^{39} \mathrm{Ar}$ isotopic analysis. These samples were selected to provide the best opportunity for obtaining useful Ar isotopic data, and to represent both the local impact flux based on compositional similarities with Apollo 16 soils and inputs from distal terranes such as the Procellarum-KREEP Terrane (PKT). The glasses analyzed for Ar isotopes are not intended to be a statistically representative sampling of the chemical compositions observed in the broader set of glasses that were measured for major and trace elements. By concentrating on particles that represent the local regolith, we were attempting to sample impact events of a similar size within a relatively restricted region, which might provide a better indication of the actual impact rate and reduce possible effects of variable transport of particles over a range of distances. A detailed description of the analytical methods is available from Norman et al. (2019) 


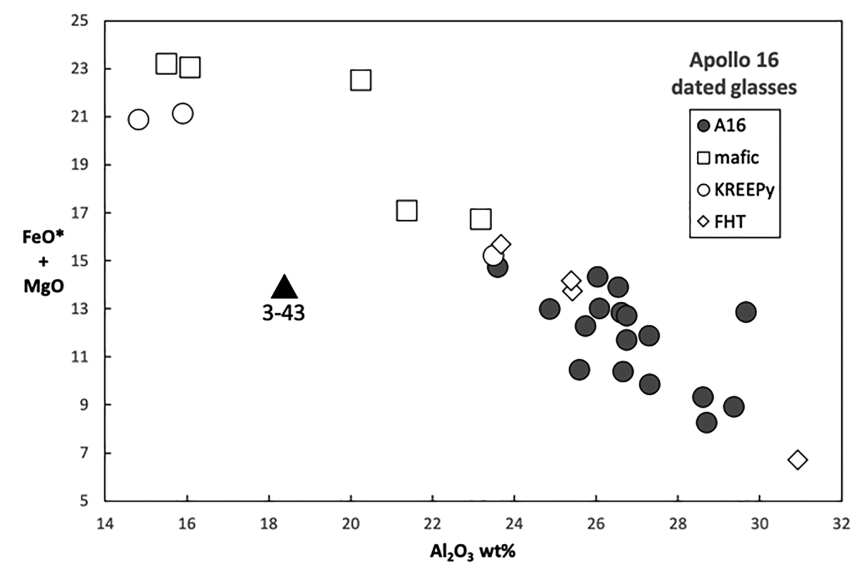

Figure 1. $\mathrm{Al}_{2} \mathrm{O}_{3}$ vs. $\left(\mathrm{FeO}^{*}+\mathrm{MgO}\right)$ contents of the Apollo 16 impact glasses analysed for this study, where $\mathrm{FeO}^{*}=$ total $\mathrm{Fe}$. See the text for description of the compositional groups and the legend.

\section{Results}

\subsection{Petrography}

Size measurements of the 30 glasses selected for Ar isotopic analysis and pre-analysis photographs of the particles are documented by Norman et al. (2019). Long dimensions of the particles ranged from 147-938 $\mu \mathrm{m}$ and ratios of long/short dimensions from 1.00-2.32. Particles with long dimensions of $<350 \mu \mathrm{m}$ tend to be more equant with a long/short ratio $\sim 1$ whereas the larger particles tended to be more elongate as indicated by larger values of long/short axis dimensions.

\subsection{Major and Trace Element Chemistry}

The $\mathrm{Al}_{2} \mathrm{O}_{3}$ contents of the glasses reported here range from 14.1-30.9 wt\% (Table 1; Figure 1). Trace element concentrations span a broad range (e.g., Th = 0.1-17.4 ppm, Sc = 2.1-66.1 ppm; Table 1, Figure 2). The range of compositions observed in these glasses is similar to that observed in lunar meteorites (Figure 2).

For convenience of discussion, four compositional groups were defined based on major and trace element characteristics (Table 1). The most populous group ( $\mathrm{n}=17)$, designated 'A16', is compositionally similar to Apollo 16 soils and impact melt rocks collected at the site (Figure 2). The bulk compositions $\left(\mathrm{Al}_{2} \mathrm{O}_{3}\right.$ 23.6-29.7 wt\%; $\left.\mathrm{FeO}=4.0-7.3 \mathrm{wt} \%\right)$ and incompatible element contents (e.g., Th 0.9-2.7 ppm, Ce 15.6-42.9 ppm) of these glasses correspond closely to those of the Apollo 16 soils (Korotev, 1997; McKay et al., 1991). The $\mathrm{CaO} / \mathrm{Al}_{2} \mathrm{O}_{3}$ of these particles are 0.48-0.62, consistent with a highlands source terrane for these glasses (Zeigler et al., 2006), and their Mg\# ranges from 58.5-70.7.

Five particles were classified as 'mafic'. These glasses have lower $\mathrm{Al}_{2} \mathrm{O}_{3}$ (15.5-23.3 wt\%) and correspondingly higher $\mathrm{FeO}$ and $\mathrm{MgO}$ than the $\mathrm{A} 16$ group (Figure 1). Their $\mathrm{Mg} \#(=100 *$ molar $\mathrm{MgO} /(\mathrm{MgO}+\mathrm{FeO})$ ) ranges from 36.6-63.6. Their $\mathrm{CaO} / \mathrm{Al}_{2} \mathrm{O}_{3}$ ratios (0.58-0.74) are slightly higher than those of the $\mathrm{A} 16$ group but their $\mathrm{Ti}, \mathrm{Cr}, \mathrm{V}, \mathrm{Sc}$ and incompatible element contents are within the range of the A16 compositions (Table 1). It should be noted that these compositions are much less mafic than the majority of Apollo 16 glasses studied by Zeigler et al. (2006).

Three glass particles were classified as 'KREEPy' due to their elevated concentrations of incompatible elements. These glasses have 14.8-23.5 wt $\% \mathrm{Al}_{2} \mathrm{O}_{3}$, and $\mathrm{FeO}+\mathrm{MgO}$ contents similar to those of the 'mafic' group, although their Sc, V, Cr, and $\mathrm{Mn}$ contents are notably higher (Table 1). The $\mathrm{CaO} / \mathrm{Al}_{2} \mathrm{O}_{3}$ ratios of the KREEPy glasses range from 0.58-0.64 and their $\mathrm{Mg} \# \mathrm{~s}$ are 53.6-58.2. Another

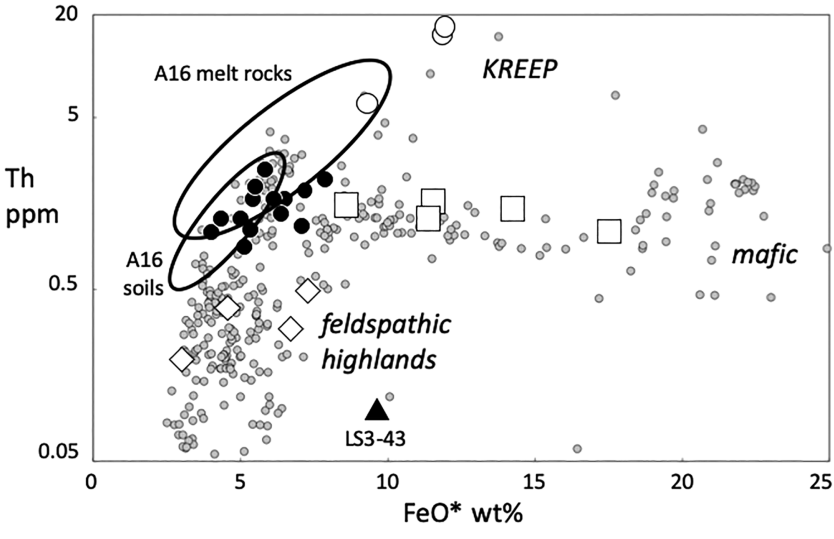

Figure 2. $\mathrm{FeO}^{*}$ vs. Th contents of the glasses analysed for this study compared to the compositions of Apollo 16 soils (Korotev, 1997; McKay et al., 1991), impact melt rocks (Korotev 1994; Norman et al. 2010), and lunar meteorites (small gray circles; data courtesy of Randy Korotev, http:// meteorites.wustl.edu/lunar/chemclass/index.htm). four glasses have major element compositions similar to those of the A16 group but with much lower abundances of incompatible elements (Figure 2, Table 1). These glasses were designated as 'FHT' to indicate their compositional affinity with the Feldspathic Highlands Terrane (Jolliff et al. 2000). Finally, sample 3-43 is anomalous in having a very high $\mathrm{CaO} / \mathrm{Al}_{2} \mathrm{O}_{3}(1.28)$ and high concentrations of mafic trace elements such as Sc and Cr. Its normative mineralogy is that of an olivine gabbro (39.7\% plagioclase, $45.7 \%$ diopside, $11.5 \%$ olivine) with an Mg\# of 61.3 (Norman et al., 2019).

Trace element compositions indicate the presence of diverse lithologic components in the source terranes of the parent craters. For example, $\mathrm{Ti} / \mathrm{Sm}, \mathrm{Sc} / \mathrm{Sm}$, and $\mathrm{Sr} / \mathrm{Ba}$ ratios are correlated with incompatible element concentrations, with the KREEPy glasses having low values of these ratios and the FHT compositions having higher values consistent with a greater proportion of ferroan anorthosite in their source terranes (Figure 3). The A16 and 'mafic' glasses have trace element compositions that are intermediate between the KREEPy and FHT groups. Sample 3-43 has the highest $\mathrm{Ti} / \mathrm{Sm}$ and $\mathrm{Sc} / \mathrm{Sm}$ ratios observed in this study. The REE patterns (Figure 4) show that (1) the KREEPy glasses have the highest 

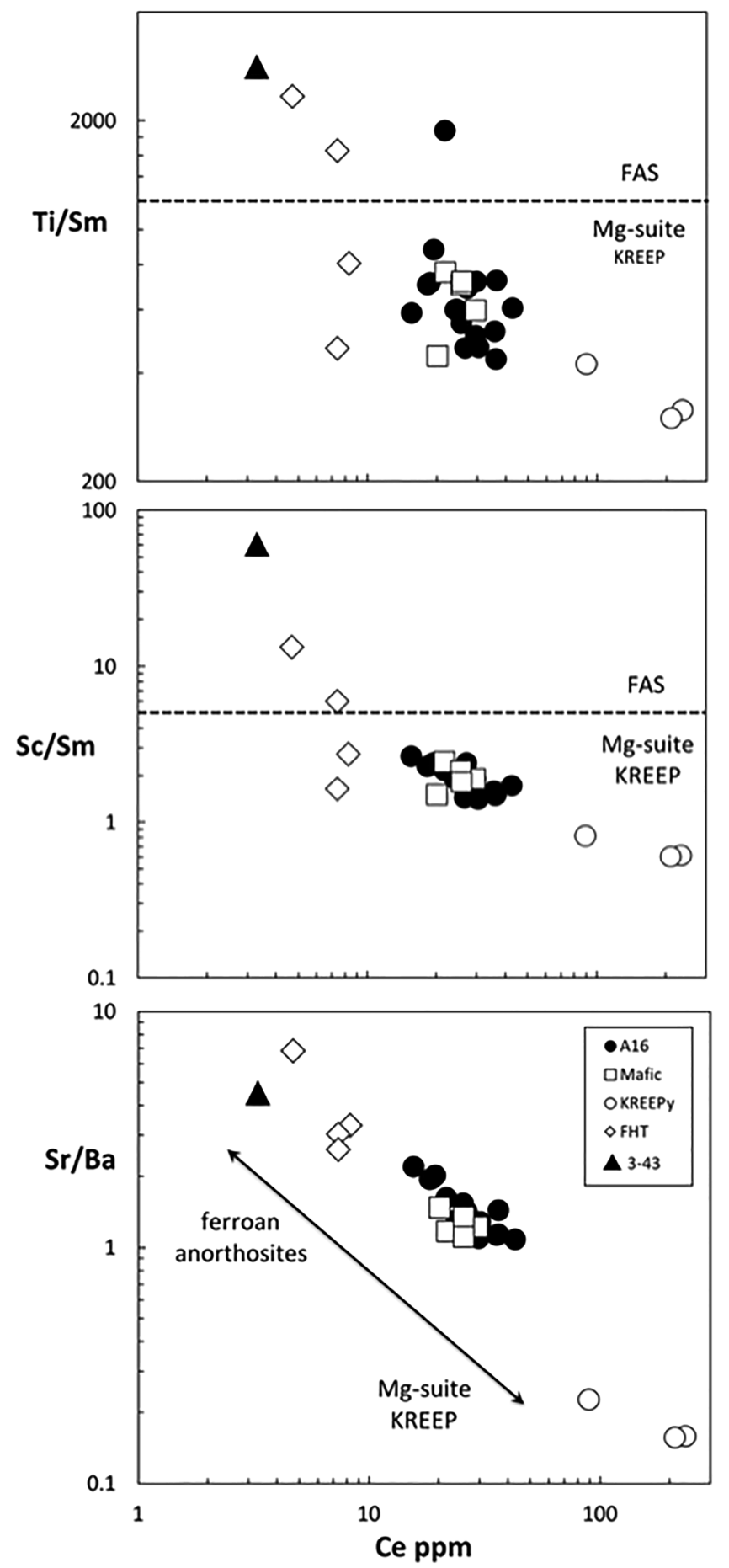

Figure 3. Ti/Sm, Sc/Sm, and $\mathrm{Sr} / \mathrm{Ba}$ ratios vs. Ce contents of the 66031 glasses studied here. The data are consistent with a diverse suite of crustal lithologies contributing to these glasses. FAS $=$ ferroan anorthositic suite. concentrations and deepest negative Eu anomalies, (2) the FHT glasses have the lowest concentrations and distinctive positive $\mathrm{Eu}$ anomalies, and (3) the A16 and 'mafic' glasses have compositions that are intermediate between the KREEPy and FHT compositions. Sample 3-43 is unique in being depleted in LREE and apparently having a slight positive Eu anomaly.

A few of the glasses have anomalously low $\mathrm{SiO}_{2}$ and alkalies, as reflected in their Si-undersaturated normative mineralogy (see data in Norman et al., 2019). This probably reflects loss of volatile elements, including $\mathrm{Si}$ and $\mathrm{Na}$ during impact melting, which may compromise the calculated normative mineralogy.

\subsection{Ar isotopes}

Twenty-seven particles yielded Ar isotopic data that provide useful constraints on their formation ages. Of these, 23 yielded acceptable plateau or mini-plateau ages (Figure 5; data for the individual samples are presented by Norman et al., 2019) that range from $142 \pm 26 \mathrm{Ma}$ for sample 1-21 to $4372 \pm 270$ Ma for sample 3-15 (Table 2). Three additional particles (2-43, 2-53, 2-71) yielded very small amounts of ${ }^{40} \mathrm{Ar}$ and total fusion ages of $149 \pm 672 \mathrm{Ma}, 137 \pm 111 \mathrm{Ma}$ and $294 \pm 34 \mathrm{Ma}$, respectively. There is good agreement between the trapped-Ar corrected plateau and total fusion ages across these samples (Figure 6). In addition, 3-43 yielded measurable trapped ${ }^{36} \mathrm{Ar}$ but no ${ }^{40} \mathrm{Ar}$ and so was assigned a zero age with no associated uncertainty. These ages are notionally interpreted as the formation age of the particle in an impact-melting event, although see Section 4.2 for additional discussion. Three glasses (3-25, 3-32, and 3-53) appeared to be either heterogeneous, as indicated by inconsistent apparent ages with very large uncertainties for the individual heating steps, or highly disturbed; no ages were assigned to these glasses.

Formation ages of the glasses studied here range from recent (effectively zero age) to $\sim 4.4 \mathrm{Ga}$. Relatively young ages are most common with 16 of the 27 dated glasses (59\%) having formation ages of $\leq 1000 \mathrm{Ma}$ and 10 of these having ages $<500 \mathrm{Ma}$ (Figure 7). Similar distributions are seen in the individual compositional groups although although the smaller number of samples in each group makes definition of the distribution less precise. For example, more than half $(n=9)$ of the A16 group glasses have formation ages <1000 Ma (Figure 7). The mafic group has 2 glasses with plateau ages of $\sim 950 \mathrm{Ma}$, and one each with ages of 1240,2560 , and $3720 \mathrm{Ma}$, whereas the KREEPy and FHT groups both have 2 samples with ages of $<500 \mathrm{Ma}$ and one particle each with ages of $3862 \mathrm{Ma}$ and $1738 \mathrm{Ma}$, respectively. There are no obvious correlations between formation age and either bulk composition or size of these particles (Figure 8). The younger glasses include both mafic and felsic compositions, and there is a wide range of ages in glasses that have similar compositions. In terms of size, the smaller glasses (short axis $\sim 100-300 \mu \mathrm{m}$ ) span the range of observed ages and the largest glasses (short axis $\sim 500-600 \mu \mathrm{m}$ ) yielded both young and old ages.

The data also allow calculation of ${ }^{38} \mathrm{Ar}$ cosmic ray exposure ages, which constrain the integrated lifetimes of the particles within the upper $\sim 1 \mathrm{~m}$ of the regolith (Reedy et al., 1983). Only half of the analysed particles yielded statistically valid ${ }^{37} \mathrm{Ar} /{ }^{36} \mathrm{Ar}$ vs. ${ }^{38} \mathrm{Ar} /{ }^{36} \mathrm{Ar}$ isochrons that allow calculation of the exposure ages presented in Table 2. For the glasses with plateau and/or isochron ages $<500 \mathrm{Ma}$, their exposure ages are within a factor of $\sim$ two of their formation ages. Impact glasses with older plateau and/or isochron ages, however, appear to have spent a relatively small fraction of their 

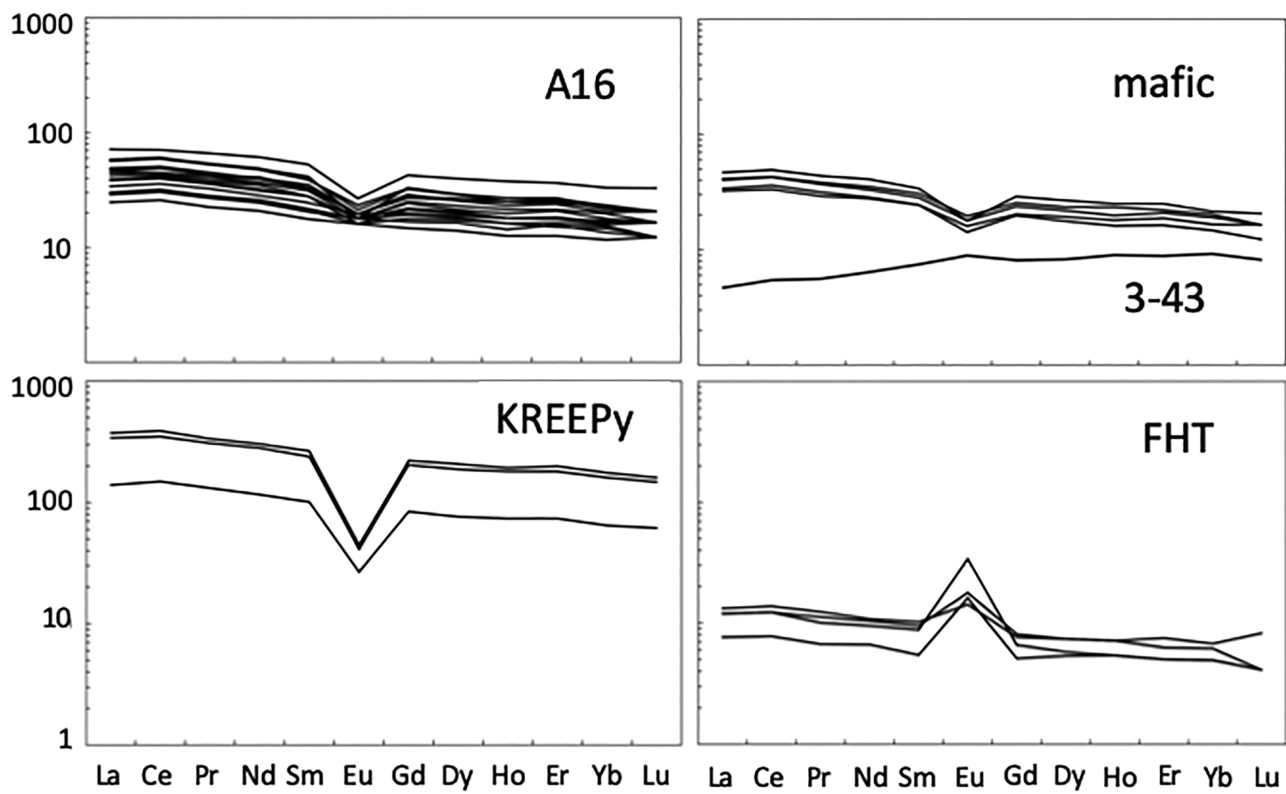

Figure 4. REE patterns of the 66031 glasses sorted by compositional group. All of the glasses have LREE-enriched patterns except for 3-43, which is LREE-depleted.

lifetime within the top metre of the regolith as indicated by their younger exposure ages relative to their plateau and/or isochrons ages (Figure 9).

\section{Discussion}

\subsection{Provenance}

The compositions of lunar impact glasses indicate a predominantly regional provenance, with a substantial fraction having 'exotic' compositions indicating distant source craters (Delano et al., 2007; Korotev et al., 2010; Norman et al., 2012; Zellner et al., 2002). For example, Delano et al. (2007) estimate that up to 30\%
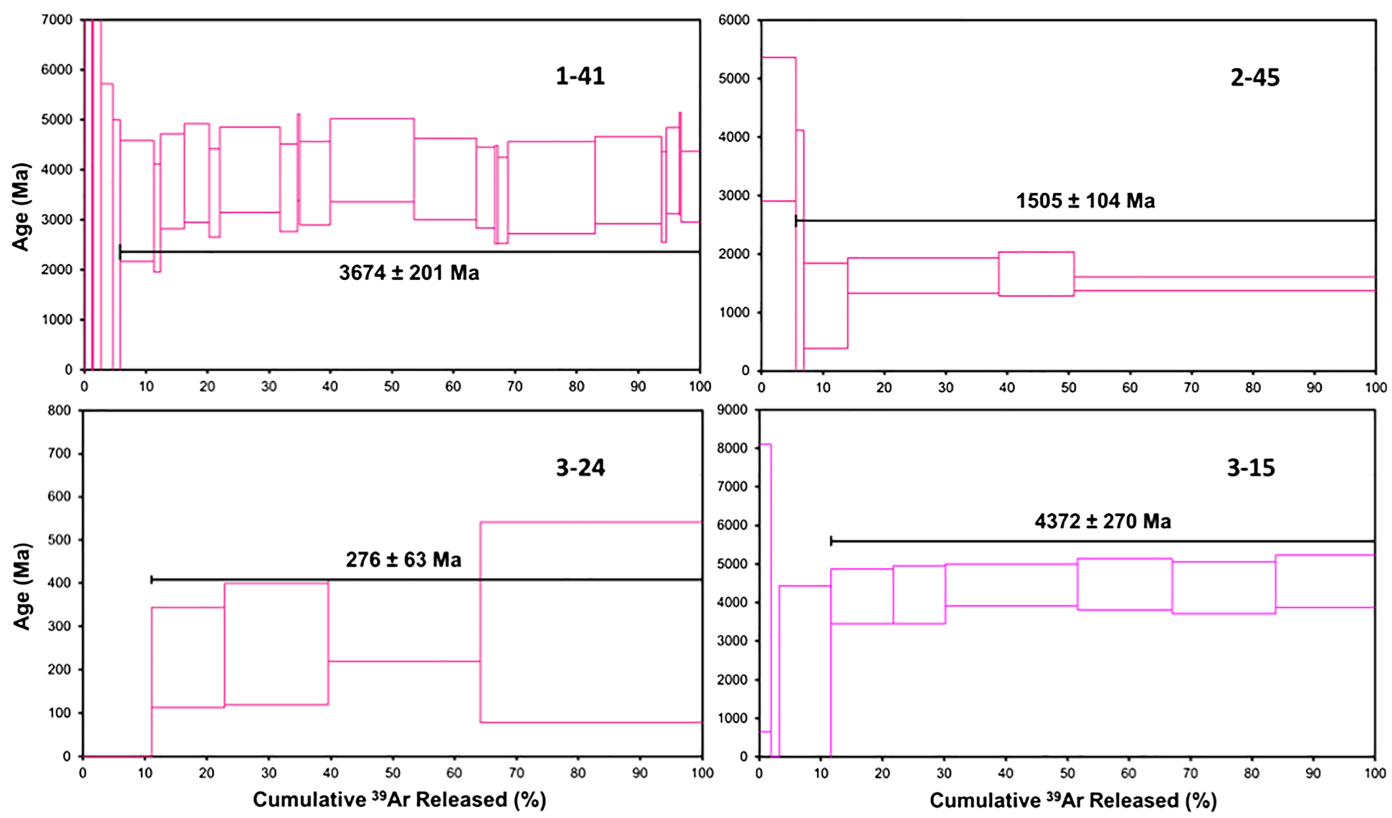

Figure 5. Reprersentative Ar release spectra obtained from the step-heating experiments on the Apollo 16 impact glasses studied here. 

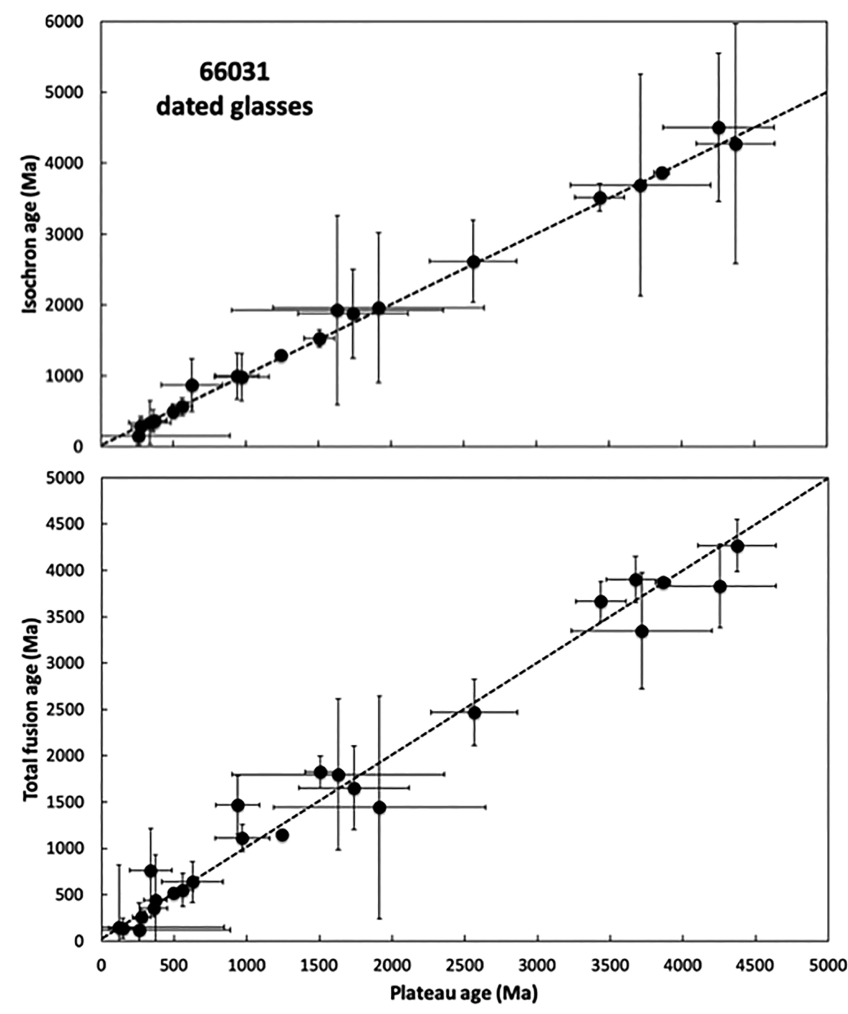

Figure 6. A comparison of plateau ages vs. the isochron and total fusion ages obtained by this study. of Apollo 16 regolith glasses may be exotic, whereas Korotev et al. (2010) concluded that $75 \%$ of the Apollo 16 impact glasses had compositions substantially different from regolith collected at the landing site and were probably formed by impact events that occurred 10's-100's of km away from the site. Considering that the abundant $\mathrm{cm}$-thick glass coatings and large melt bombs found at the Apollo 16 site were probably produced by South Ray crater (Morris et al., 1986), which is only $700 \mathrm{~m}$ in diameter and $\sim 6 \mathrm{~km}$ from the landing site, considerably longer transport distances for the much smaller regolith glass particles seems conceivable.

The lack of comprehensive chemical data from previous glass dating studies has hindered the ability to constrain the provenance of individual glasses. For example, the major element data acquired by Levine et al. (2005) mainly allow for discrimination of volcanic versus impact origins. Delano et al. (2007) suggested that high-K impact glasses with ages of $\sim 3.76 \mathrm{Ga}$ found at Apollo 16 soils were sourced from a large $(\sim 100 \mathrm{~km}$ diameter?) crater in the PKT. Of the glasses analysed in this study, those in the A16 group are most likely to be sourced from targets with a compositional affinity to Apollo 16 regolith. Their compositions are similar to those of the Cayley-type soils that were collected from the central and southern stations of the landing site, including the host soil from which these particles were taken. Although there is limited information about the scale and magnitude of compositional variations in the vicinity of the landing site, Fischer \& Pieters (1996) found that the surface compositions of the Cayley plains are reasonably homogeneous within their study area, which was within $\sim 100 \mathrm{~km}$ of the landing site. The A16 group is therefore considered to be of predominantly local provenance.

Our A16 group also includes two particles with nominal ages of 4.2-4.3 $\mathrm{Ga}$, considerably older than the Imbrium basin $(\sim 3.9 \mathrm{Ga})$. Although the uncertainty on 3-52 just overlaps with the Imbrium age, these glasses are intriguing because the Cayley plains in the vicinity of the Apollo 16 site probably formed as Imbrium ejecta, possibly as a debris surge deposit (Korotev, 1997; Spudis et al., 1988). However, the fraction of primary Imbrium ejecta in these deposits is not well constrained, and the presence of older glasses with Cayley-like compositions suggests that such compositions may have been present on the lunar surface prior to the Imbrium impact. If so, Imbrium might have resurfaced this region of the central nearside lunar highlands without emplacing substantial amounts of new material as primary ejecta.

The provenance of the other compositional groups is less clear. The most obvious candidates for 'exotic' particles are the three glasses with KREEPy compositions. They are more mafic and richer in incompatible trace elements than the Apollo 16 regolith, and more similar compositionally to soils collected at Apollo 14, a distance of about $1000 \mathrm{~km}$ away. Although KREEP-rich melt rocks were collected at the Apollo 16 site, the compositions of the impact glasses studied here are distinct from those melt rocks. Based on the spatial distribution of KREEP-rich compositions on the Moon (Prettyman et al., 2006), these glasses were probably sourced from the PKT. A source within the PKT might imply delivery of the particles to the Apollo 16 site by large craters (Delano et al., 2007). Two of the KREEPy glasses are young (276 \pm 63 and $498 \pm 14 \mathrm{Ma}$ ) and their ages differ by more than their combined uncertainties, so presumably they represent two distinct impact events. However, large young craters are rare on the Moon (Kirchoff et al., 2013) and there are few large candidate craters that might have produced these glasses, especially assuming two discrete events. For comparison, the $95 \mathrm{~km}$ diameter Copernicus crater is $\sim 800 \mathrm{Ma}$, much older than either of the two young KREEPy glasses.

Alternatively, smaller craters might deliver glasses over long distances more efficiently than currently appreciated. As an example, the KREEP-rich lunar meteorite SaU 169 may have been launched from the Moon 340,000 years ago by a small (few km) impact (Gnos et al., 2004). Interestingly, and probably coincidently, SaU 169 also records an impact event at 200 Ma similar to the age of one of the KREEPy 

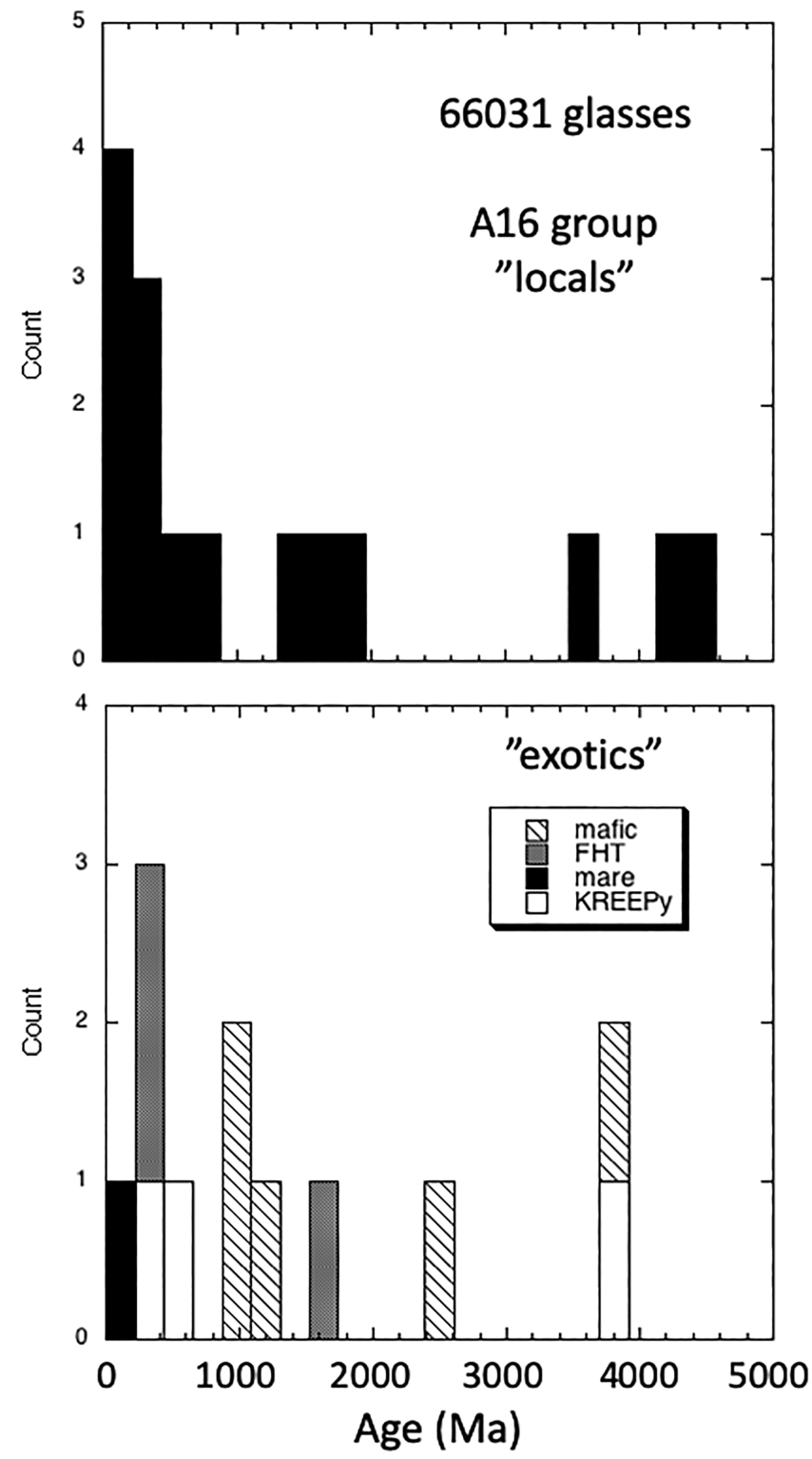

Figure 7. Frequency histograms of preferred formation ages (Table 3) for the A16 group, considered to be locally derived, compared to those for all other compositional groups combined, which are considered to be 'exotic' to the landing site. glasses. Other lunar meteorites also have very young blast-off ages and may have been launched by craters with final diameters of $2-5 \mathrm{~km}$ or less (Warren, 1994).

The provenance of the FHT and 'mafic' group glasses is less apparent. The Descartes Formation and related breccias collected at the northern and southern stations of the Apollo 16 traverses are more aluminous and have lower Th and incompatible trace element compositions than the Cayley samples (Norman 1981; Korotev 1982). In addition, there are substantial outcrops of anorthositic rocks on the Kant Plateau to the east of the Apollo 16 site (Andre and El-Baz, 1981), both of which could provide source terranes for FHT-type glasses. For the mafic glasses, the LREEenriched compositions of the analysed particles are not very different from those of the A16 group but their Th contents of 1.1-1.8 ppm do not provide a strong discriminant for a source terrane in the central nearside lunar highlands based on regional data provided by Lunar Prospector (Korotev et al., 2010). The compositions of the FHT and mafic groups could, therefore, be consistent with either a regional origin or with impacts into local components with more mafic and/or more anorthositic substrates that could be excavated by craters such as Abulfed (more mafic; $62 \mathrm{~km}$ diameter, $\sim 200 \mathrm{~km}$ south of the landing site) and South Ray (more anorthositic; $0.7 \mathrm{~km}$ diameter, $\sim 6 \mathrm{~km}$ from the landing site) (Fischer \& Pieters 1996). Considering these uncertainties, we assign the A16 group to a 'local' provenance and the mafic, FHT, and KREEPy glasses as 'exotic' compositions.

Particle 3-43 has a high $\mathrm{Ca} / \mathrm{Al}$, very low Ti, and a LREE-depleted pattern. These compositional characteristics are consistent with a mare source but could also allow a terrane consisting of highlands cumulates. Remote sensing data indicates areas of gabbroic (high $\mathrm{Ca} / \mathrm{Al}$ ) compositions in the lunar highlands (Lucey \& Hawke, 1988) and mineral compositions in Apollo 17 melt rocks also show that gabbroic lithologies are more common in the lunar crust than indicated by their abundance in the Apollo sample collection (Ryder et al., 1997). However, a mare source terrane still seems more likely considering the limited areal extent of the exposed gabbroic units in the highlands (Lucey and Hawke 198). Theophilus, a 100 $\mathrm{km}$ diameter crater located proximal to Mare Nectaris, has been suggested as the source crater for some mare basalt fragments found at the Apollo 16 site but its stratigraphic age of $\sim 1-3 \mathrm{Ga}$ (Eratosthenian) would disqualify it as the source of glass particle 3-43, assuming its inferred zero age is correct. Zeigler et al. (2006) list a number of other potential source craters for Apollo 16 glasses with mare affinities, but additional work is necessary to evaluate the provenance and potential source craters of 3-43 and other mare glasses found at the Apollo 16 site.

\subsection{Formation Ages}

A striking feature in the age distribution of the samples analysed here is the abundance of young ages, similar to that observed in previous studies of lunar regolith glasses (Culler et al., 2000; Levine et al., 2005; Nemchin et al., 2013; Nguyen \& Zellner, 2019; Norman et al., 2012, 2014; Zellner, 2017) (Figure 7). Based on data from this study, glasses younger than $500 \mathrm{Ma}$ are most abundant with $38 \%$ of the acceptable ages falling within this range. A preponderance of young ages appears to be a general feature of impact glasses in the lunar regolith, at least on the nearside where the Apollo samples were collected. Such an age distribution might reflect either an elevated impact flux, regolith dynamics such as a preservation bias toward young events, or open-system behaviour of the isotope systems, perhaps related to diurnal or transient heating of the lunar regolith. In the following sections, we discuss aspects of these possibilities. 

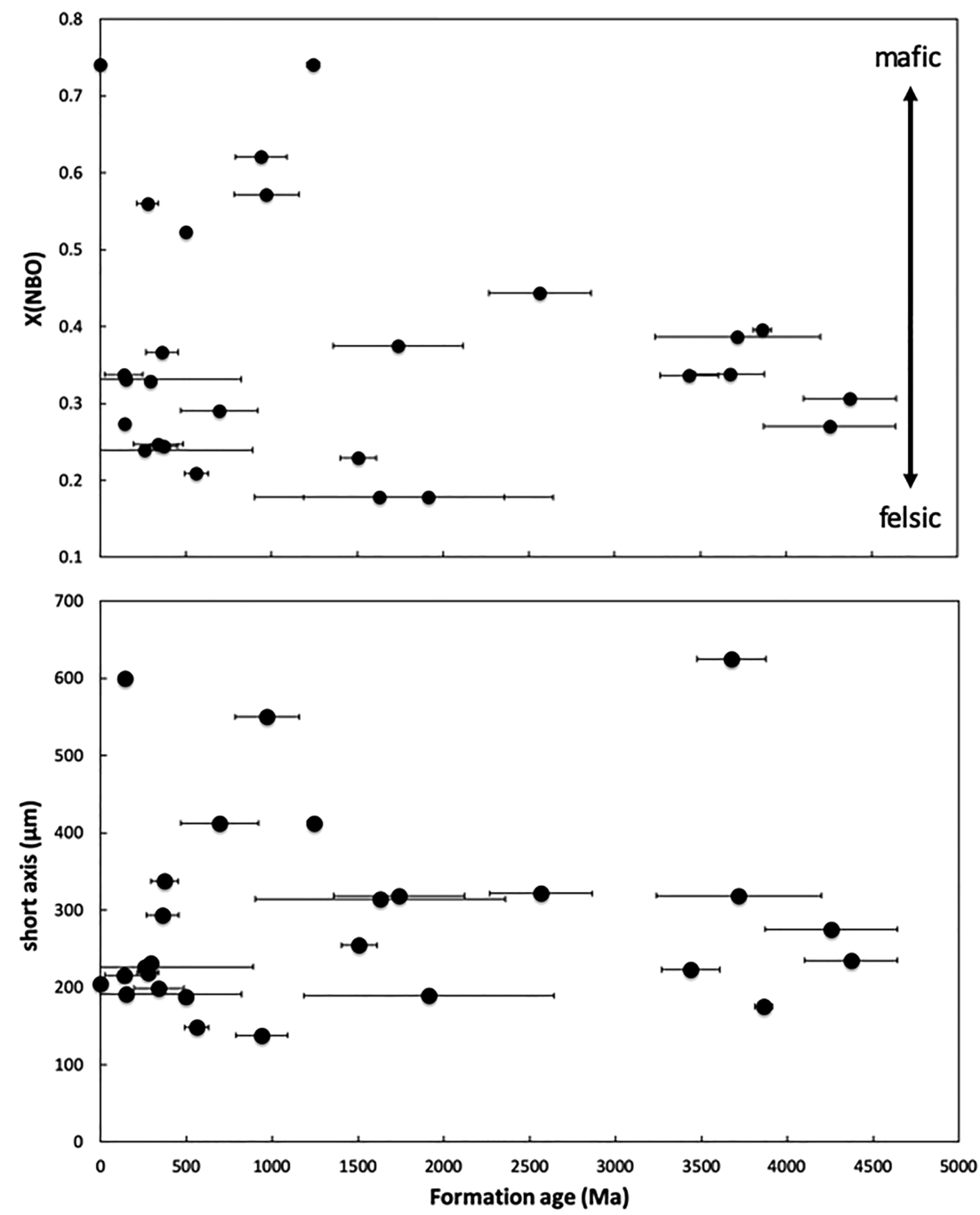

Figure 8. Formation ages of the glasses studied here vs. their bulk composition and size as expressed by $\mathrm{X}(\mathrm{NBO})$ and the length of their short axis.

\subsubsection{Contributions from duplicate glasses}

A straightforward interpretation of the age distribution in lunar regolith glasses would be that it reflects an increase in the impact rate over the last $1 \mathrm{Ga}$ (Culler et al., 2002: Levine et al., 2005; Zellner et al., 2009b; Norman et al., 2012). An increase in the impact rate within the last $\sim 500$ Ma has been inferred from the distribution of lunar craters (Mazrouei et al., 2019), and a number of discrete events with ages $\leq 1050$ Ma have been suggested based on the age distribution of lunar regolith glasses (Zellner, 2017; Zellner et al., 2009b; Zellner \& Delano, 2015). Clusters of lunar regolith glass ages might be related to break-up events in the asteroid belt such as the one that affected the L-chondrite parent body at 0.5 Ma. However, a 1:1 correspondence between the frequency of regolith glass ages and specific impact events on the Moon seems unlikely as the apparent excess of young ages in the lunar glasses would imply a factor of 4-10 higher impact rate in the Phanerozoic relative to the Proterozoic (Culler et al., 2000; Huang et al., 2018) compared to the factor of 2-3 inferred by Mazrouei et al. (2019) from crater distributions.

Alternatively, young events may be over-represented in the impact glass population due to production of multiple particles in the same event. For example, the numerous examples of glass coatings and glass bombs collected at the Apollo 16 site all seem to be melt produced by the South Ray crater event at $2 \mathrm{Ma}$ (See et al., 1986; Morris et al., 1986) As another example of multiple glass particles produced by a single event, Delano et al. (2007) concluded that four glass fragments with formation ages of $~ 3.73-3.78 \mathrm{Ga}$ and exotic KREEP-rich 


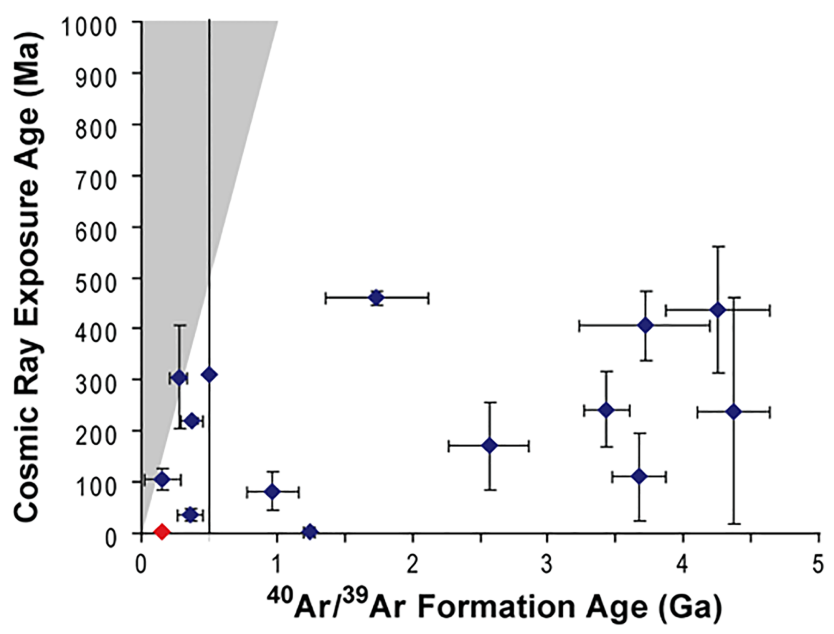

Figure 9. A comparison of ${ }^{40} \mathrm{Ar} /{ }^{39} \mathrm{Ar}$ formation ages and ${ }^{38} \mathrm{Ar}$ exposure ages for the Apollo 16 glasses studied here.

major element compositions were produced by a single large and distant impact. Using a statistical comparison of their compositions and ages, we evaluated the possibility that individual impact events might have contributed multiple glass particles to the samples studied here. The trace element abundances acquired in this study allow for additional constraints on possible duplicate particles.

For this analysis, the composition and formation age of each particle was compared with all of the other dated particles using a chi-squared method to determine the probability that the pair has the same age and composition within analytical uncertainty (Hui, 2011). This approach assumes that glasses produced by the same event have identical compositions and ages, and that a probabilistic match of $>5 \%$ is statistically significant. The effective degrees of freedom determined using this method is 18 . When applied to the dated glasses, a matrix of probabilistic matches of their compositions $\left(\mathrm{P}_{\mathrm{c}}\right)$ and ages $\left(\mathrm{P}_{\mathrm{a}}\right)$ was obtained (Figure 10). There are five potential pairs with $\mathrm{P}_{\mathrm{c}}$ and $\mathrm{P}_{\mathrm{a}}$ of $5-50 \%$, and 3 potential pairs with $\mathrm{P}_{\mathrm{c}}$ and $\mathrm{P}_{\mathrm{a}}>50 \%$ (Figure 10). Interestingly, none of these have ages $\leq 1 \mathrm{Ga}$; rather they all have ages that range between 1505-4372 Ma. If the potential duplicates are removed, the age distribution indicates an even more dramatic increase in young ages, much like that observed in glasses from Apollo 12 (Levine et al., 2005). Particles 1-33 and 1-41 have $\mathrm{P}_{\mathrm{a}}$ and $\mathrm{P}_{\mathrm{c}}>85 \%$, making them the most likely duplicate pair even though their FeO contents, $\mathrm{Mg} \# \mathrm{~s}$ and some trace element contents appear to be different (Table 1). The formation ages of these particles are $\sim 3.7 \mathrm{Ga}$, considered to be the tail of the Late Heavy Bombardment (Wetherill, 1975, 1977). While the apparent age of this pair overlaps with those of the KREEP-rich shards reported by Delano et al. (2007), we suggest that the glasses studied here represent a different impact event because their compositions are very different (i.e., 21.4-23.6 wt $\% \mathrm{Al}_{2} \mathrm{O}_{3}$ for particles 133 and 1-41 vs. 10.6-13.2 wt\% $\mathrm{Al}_{2} \mathrm{O}_{3}$ for the glasses studied by Delano et al., 2007).

Overall, our results argue against production of multiple glass particles by young impacts as a significant bias on the age distribution of Apollo 16 regolith glasses. If these results are generally applicable, then multiple particles from a single impact would not strongly affect the earlier interpretations. Conversely, it suggests that older impact glasses may be more likely to be duplicates, possibly because they were formed in larger events that produced greater quantities of glassy ejecta, or that the glass-forming impact rate was higher
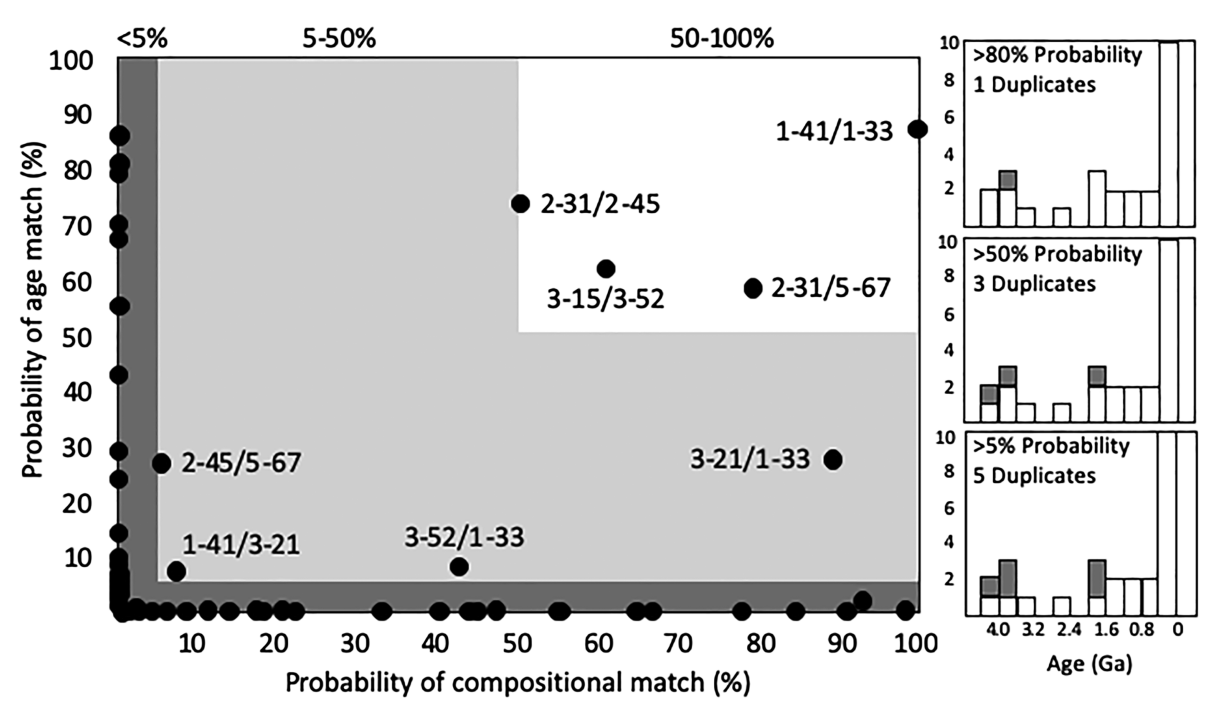

Figure 10. Plot of probability of composition versus formation age matches of impact glass pairs from this study. Pairs not of statistical significance ( $\mathrm{P}<5 \%$ ) are plotted in the dark grey region, while pairs likely to be related to the same event ( $P>50 \%$ ) fall within the white region of the diagram. The age distributions to the right show the effect of removing potentially duplicate (grey boxes) as a function of probability. Note that some particles occur in multiple pairs such that the total number of individual particles in the potentially significant pairs is eight. 
in the past. This leads to a scenario where there is a balance between preservation of the older record through duplication and burial of impact glasses versus destruction from subsequent impacts and regolith gardening. However, while it may be possible to identify potential duplicate impact glasses based on geochemical and age data, it also might be possible for such particles to actually represent distinct but spatially restricted impacts into regions where soils have similar compositions. This would be difficult to distinguish and may require additional observations to evaluate.

\subsubsection{Regolith gardening}

Regolith dynamics could introduce a preservation bias in the age distribution of regolith glasses due to destruction of older grains during impact gardening, or sequestration of grains below the zone of surficial reworking (Huang et al., 2018; Hui, 2011; Levine et al., 2005; Zellner \& Delano, 2015). Maturation of the lunar regolith depends strongly on local effects such as overturning and emplacement of new layers by small impacts. The few depth-profiles of the lunar regolith show that it is difficult to extrapolate the stratigraphy between sampling locations, even at the same landing site. Detailed observations of the Apollo 16 deep drill core 60009/10 indicate a reworking depth of $\sim 10-15 \mathrm{~cm}$ and an exposure age of $\sim 100 \mathrm{Ma}$ (McKay et al., 1991; Morris, 1978), which could be broadly consistent with the age distribution observed here. Models of regolith evolution by Huang et al. (2018) predict a depth-dependent age bias that could produce an over-abundance of young ages at the lunar surface even for at a constant impact flux, and that older glasses should be preserved at systematically greater depths.

Over the longer term, regolith glasses might be broken down into shards or fragments and perhaps not selected for studies that emphasize analysis of spherules. Zellner and Delano (2015) hypothesized that lunar impact glasses are prone to break into shards or fragments due to the high internal stresses introduced by rapid quenching. They predicted that spherical particles would have younger ages, thereby introducing a selection bias on the ages if spherical particles were analysed in preference to shards. Although classification of lunar impact glass morphology can be somewhat subjective, our impression is that the younger glasses studied here tend to have a more pristine appearance compared to the older glasses. For example, the youngest glasses have cleaner exterior surfaces compared to the older glasses, which tend to have a darker and more mottled appearance as observed under a binocular microscope prior to analysis possibly due to space weathering during residence in the regolith (Escobar-Cerezo et al., 2018). The oldest (>2000 Ma) glasses tend to have more irregular shapes, although shapes that reflect primary quenched melt droplets are still preserved. Additional studies that apply internally consistent criteria and methods to large sample sets are needed to elucidate relationships of exposure ages to the stratigraphy of lunar soils (McKay et al., 1991).

A comparison between formation and exposure ages of the impact glasses with formation ages $<\sim 500 \mathrm{Ma}$ (Figure 9) suggests that these particles resided in the upper 1-2 $\mathrm{m}$ of the regolith for most of their lifetimes, but older glasses spent as much as $75-90 \%$ of their lifetimes at considerably greater depths or shielded in some other way. In contrast, many of the Apollo 12 and 14 glasses studied by Levine et al. $(2005,2007)$ and Culler et al. (2000), respectively, have older absolute exposure ages. For example, all of the exposure ages reported here are <500 Ma whereas many of the Apollo 12 and 14 glasses have exposure ages of 1000-2000 Ma (Levine et al., 2007). While the greater abundance of glasses with longer exposure histories in the submature Apollo 12 (12023) and Apollo 14 (14163) soils compared to the highly mature soil 66031 studied here may seem counter-intuitive, the distribution of cosmogenic nuclides, including ${ }^{38} \mathrm{Ar}$, with depth in lunar soils is highly variable and depends strongly on the occurrence of relatively small impact events in the vicinity of the sampling site that can overturn or add new layers at the local scale. For example, a deep drill core at the Apollo 15 site revealed a regolith profile that had lain virtually undisturbed for at least $420 \mathrm{Ma}$, whereas cores at the Apollo 16 and 17 sites indicate more complicated exposure histories involving both ancient and recent emplacement of less mature layers and substantial increases in the ${ }^{38} \mathrm{Ar}$ of bulk fines with depth (Curtis and Wasserburg, 1975; Curtis \& Wasserburg, 1977; Bogard \& Hirsch, 1975; Pepin et al., 1974, 1975; Hidaka et al., 2000).

Although individual particles can have exposure histories very different from that of the bulk soil (e.g., Curtis \& Wasserburg, 1977), the longer exposure histories of Apollo 12 and 14 glasses relative to those from the Apollo 16 soil studied here may reflect excavation of deeper regolith by young craters. At the Apollo 12 site, regolith sample 12023 was collected on the rim of Sharp crater ( $<10 \mathrm{Ma}$ ) and regolith around Apollo 14 site appears to carry a significant component of ejecta from Cone crater ( $30 \mathrm{Ma}$; Arvidson et al., 1975). In 

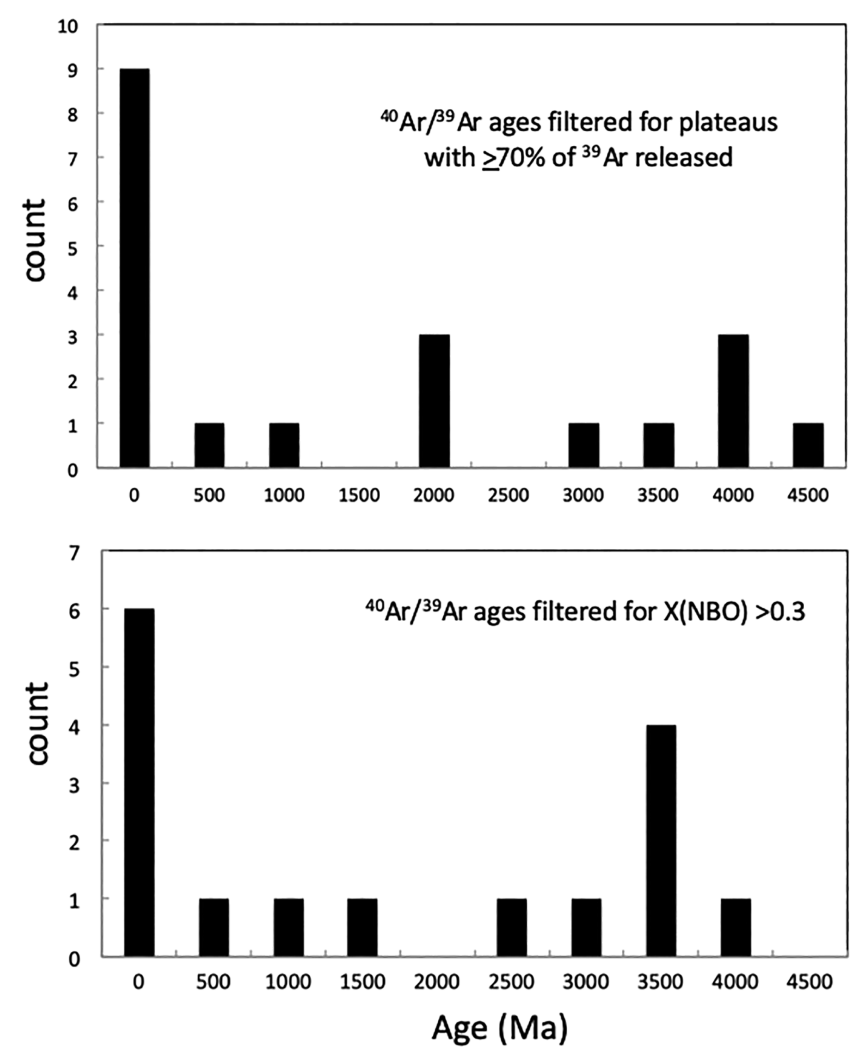

Figure 11. ${ }^{40} \mathrm{Ar} /{ }^{39} \mathrm{Ar}$ ages obtained by this study filtered for plateaus with $>70 \%$ of the ${ }^{39}$ Ar released, and for relatively mafic compositions with $\mathrm{X}$ $(\mathrm{NBO})>0.3$. These filters should produce data with the highest confidence of reflecting primary formation ages of the regolith glasses. contrast, the Apollo 16 soil studied here (Station 6) was collected on the rim of a shallow, subdued crater in a relatively flat area well away from any young blocky craters. This suggests that the contrasting exposure histories of regolith glasses from the Apollo 12, 14, and 16 sites may be related to local overturn events that influence the time-integrated sampling depths within the regolith at specific sites Additional studies that address this issue directly are needed, perhaps through stratigraphic studies of lunar cores with variable maturities and reworking histories.

\subsubsection{Diurnal heating}

Another factor that might contribute to the excess of young ages in lunar regolith glasses is diffusive loss of Ar during diurnal heating or impact events (Shuster \& Cassata, 2015). Diffusive loss of argon from individual grains during diurnal heating and transient impact heating was modelled by Gombosi et al. (2015) and implications of diurnal heating for dating lunar regolith glasses was discussed by Zeller and Delano (2015). Effects of regolith gardening and diurnal heating may be closely related (Zellner \& Delano, 2015).

The diffusion data of Gombosi et al. (2015) suggest that aluminous glasses like those typical of the Apollo 16 regolith should lose Ar relatively quickly at the time-integrated temperatures experienced at the lunar surface during diurnal heating, so a bias toward younger ages might be expected, especially in more mature soils. Regolith sample 66031 is one of the most mature soils sampled by the Apollo missions, so transient heating by impacts is unlikely to be a significant factor affecting glasses in this sample of lunar regolith but the long-term effects of diurnal heating might be important. However, such effects are difficult to discern in the data obtained by this study. Gombosi et al. (2015) predict that aluminous glasses lose Ar more easily than those with more mafic compositions, and that smaller glasses are reset more easily than larger particles. In contrast to these predictions, our data show no correlations between formation age, grain size, or bulk composition as expressed by X (NBO), or the fraction of ${ }^{39} \mathrm{Ar}$ that defines the ${ }^{40} \mathrm{Ar} /$ ${ }^{39} \mathrm{Ar}$ plateau age. For example, if the data are filtered for $>70 \%{ }^{39} \mathrm{Ar}$ in the plateau (to which the degree of ${ }^{40} \mathrm{Ar}$ diffusive loss would not have affected the formation age) or to include only the more mafic compositions with X $(\mathrm{NBO})>0.3$ as recommended by Gombosi et al. (2015), the age distributions still show an excess of young ages (Figure 11). Interestingly, both of these filtered datasets show a greater abundance of ages around 3.5-4.0 Ga, a time of particular significance for the lunar Terminal Cataclysm hypothesis (Tera et al., 1974; Tera \& Wasserburg, 1974).

Importantly, an excess of young ages is also evident in the $\mathrm{U}-\mathrm{Th}-\mathrm{Pb}$ compositions of regolith glasses from the Apollo 11, 14, and 17 sites (Nemchin et al., 2013; Norman et al., 2012, 2014). As the diffusion of $\mathrm{Pb}$ as a $2^{+}$ cation in aluminous glass is similar to that of the more refractory elements $\mathrm{Sr}$ and $\mathrm{Ba}$ (Fanara et al., 2017) and orders of magnitude slower than that of Ar under similar conditions (Gombosi et al., 2015), it is reasonable to conclude that the young ages recorded both by the Ar and the U-Pb isotopes approximate the time of formation of the individual impact glasses. Of the three glasses studied here that did not yield useful age information, 3-25 and 3-53 appear to be heterogeneous whereas 3-32 shows both high- $\mathrm{T}$ and low-T losses. These particles are, therefore, not useful candidates for evaluating the diffusive resetting of regolith glasses by diurnal heating.

\subsection{Implications for lunar bombardment}

The ages, abundances and distribution of lunar regolith glasses must reflect the combined effects of production and preservation, but the relationships between compositions, ages, and impact flux are not well understood. For example, it is not known whether regolith glasses reflect the total integrated impact flux or if certain conditions such as size, velocity, or angle of the impactor, are necessary, perhaps analogous to terrestrial tektites. 
Modelling of spherule-producing impacts on the Earth suggest that $100 \mu \mathrm{m}$ diameter spherules are produced by impactors with diameters of 100-300 m (Melosh \& Vickery 1991), which would correspond to craters of 1-3 km diameter on the Moon, consistent with estimates considered earlier. Larger impactors such as those inferred for terrestrial Archean spherule layers (10 km; Johnson \& Melosh, 2012) would produce an abundance of young craters $\sim 100 \mathrm{~km}$ diameter on the Moon that is not observed. The predominantly local provenance implied by the compositions of lunar regolith glasses is also consistent with their formation by relatively small craters, possibly enhanced by the elevated temperatures at relatively modest pressures that can be produced in porous targets such as the lunar regolith (Jourdan et al., 2017; Wünnemann et al., 2008). As such, the age distribution of the regolith glasses cannot be compared directly with the crystalline lunar melt rocks, which reflect much larger (basin-scale?) impact events. Based on the young ages of two of the KREEPy glasses (200-500 Ma) and the one mare glass ( 0 Ma) presented here, long-distance transport over distances of $\sim 1000$ 's of $\mathrm{km}$ by relatively small impact events seems feasible. This would represent a new perspective on the significance of exotic lunar regolith glasses.

Formation of lunar regolith glasses by smaller craters would make these types of samples better suited to understanding the more recent impact history of the Moon. Many H- and L-chondrite meteorites show evidence for thermal resetting of the K-Ar isotope system at <500 Ma (Bogard et al., 1995; Swindle et al., 2014), linking the lunar regolith glasses to collisional and/or break-up events in the asteroid belt. The extent to which apparent peaks in the age-frequency distribution of lunar glasses can be related to the biogeochemical evolution of Earth (Zellner \& Delano, 2015) is a topic of continuing interest.

\section{Conclusions}

Thirty regolith glasses from the Apollo 16 regolith have been characterized for their major and trace element compositions and Ar isotopic compositions. These glasses have a wide range of compositions. About half of them record glass-forming impacts in the vicinity of the Apollo 16 landing site. Of these local provenance glasses, there is a strong peak in young $(<500 \mathrm{Ma})$ formation ages. Exotic glasses also imply a significant contribution from young impacts. Diurnal heating in the regolith does not appear to explain the observed age distribution. Further studies of lunar regolith glasses are necessary to understand this important record of impact history in the inner solar system.

\section{Acknowledgments}

The authors comply with AGU's data policy, and readers can access the data through tables presented in the text and the supporting information that accompanies this submission. Data for this study can be obtained from Interdisciplinary Earth Data Alliance (IEDA) doi:10.1594/IEDA/111339.

\section{References}

Arvidson, R., Crozaz, G., Drozd, R. J., Hohenberg, C. M., \& Morgan, C. J. (1975). Cosmic ray exposure ages of features and events at the Apollo landing sites. The Moon, 13(1-3), 259-276. https://doi.org/10.1007/bf00567518

Bogard, D. D. (2011). K-Ar ages of meteorites: Clues to parent-body thermal histories. Chemie der Erde-Geochemistry, 71(3), 207-226. https://doi.org/10.1016/j.chemer.2011.03.001

Bogard, D. D., Garrison, D. H., Norman, M., Scott, E. R. D., \& Keil, K. (1995). ${ }^{39} \mathrm{Ar} /{ }^{40} \mathrm{Ar}$ age and petrology of Chico: Large-scale impact melting on the L chondrite parent body. Geochimica et Cosmochimica Acta, 59(7), 1383-1399. https://doi.org/10.1016/0016-7037(95) 00051-z

Bogard, D. D., \& Hirsch, W. C. (1975). Noble gas studies on grain size separates of Apollo 15 and 16 deep drill cores. In Lunar and Planetary Science Conference Proceedings, (Vol. 6, pp. 2057-2083).

Culler, T. S., Becker, T. A., Muller, R. A., \& Renne, P. R. (2000). Lunar impact history from ${ }^{40} \mathrm{Ar} /{ }^{39}$ Ar dating of glass spherules. Science, 287(5459), 1785-1788. https://doi.org/10.1126/science.287.5459.1785

Curtis, D. B., \& Wasserburg, G. J. (1977). Stratigraphic processes in the lunar regolith-additional insight from neutron fluence measurements on bulk soils and lithic fragments from the deep drill cores. In Lunar and Planetary Science Conference Proceedings, (Vol. 8, pp. 3575-3593).

Delano, J. W. (1986). Pristine lunar glasses: Criteria, data, and implications. Journal of Geophysical Research - Solid Earth, 91(B4), 201-213. https://doi.org/10.1029/jb091ib04p0d201

Delano, J. W., \& Livi, K. (1981). Lunar volcanic glasses and their constraints on mare petrogenesis. Geochimica et Cosmochimica Acta, 45(11), 2137-2149. https://doi.org/10.1016/0016-7037(81)90066-1

Delano, J. W., Zellner, N. E. B., Barra, F., Olson, E., Swindle, T. D., Tibbetts, N. J., \& Whittet, D. C. B. (2007). An integrated approach to understanding Apollo 16 impact glasses: Chemistry, isotopes, and shape. Meteoritics \& Planetary Science, 42(6), 993-1004. https://doi. $\operatorname{org} / 10.1111 / \mathrm{j} .1945-5100.2007 . t b 01146 . x$

Escobar-Cerezo, J., Penttilä, A., Kohout, T., Muñoz, O., Moreno, F., \& Muinonen, K. (2018). Simulations of Effects of Nanophase Iron Space Weather Products on Lunar Regolith Reflectance Spectra. The Astrophysical Journal, 853(1), 71. https://doi.org/10.3847/1538-4357/ aaa24d

Fanara, S., Sengupta, P., Becker, H. W., Rogalla, D., \& Chakraborty, S. (2017). Diffusion across the glass transition in silicate melts: Systematic correlations, new experimental data for $\mathrm{Sr}$ and $\mathrm{Ba}$ in calcium-aluminosilicate glasses and general mechanisms of ionic transport. Journal of Non-Crystalline Solids, 455, 6-16. https://doi.org/10.1016/j.jnoncrysol.2016.10.013

Fassett, C. I. (2016). Analysis of impact crater populations and the geochronology of planetary surfaces in the inner solar system. Journal of Geophysical Research, Planets, 121(10), 1900-1926. https://doi.org/10.1002/2016je005094 
Fischer, E. M., \& Pieters, C. M. (1996). Composition and exposure age of the Apollo 16 Cayley and Descartes regions from Clementine data: Normalizing the optical effects of space weathering. Journal of Geophysical Research, Planets, 101(E1), 2225-2234. https://doi.org/ 10.1029/95je02983

French, B. M. (1998). Traces of catastrophe: A handbook of shock-metamorphic effects in terrestrial meteorite impact structures. Lunar and Planetary Institute.

Gnos, E., Hofmann, B. A., Al-Kathiri, A., Lorenzetti, S., Eugster, O., Whitehouse, M. J., et al. (2004). Pinpointing the source of a lunar meteorite: Implications for the evolution of the Moon. Science, 305(5684), 657-659. https://doi.org/10.1126/science.1099397

Gombosi, D. J., Baldwin, S. L., Watson, E. B., Swindle, T. D., Delano, J. W., \& Roberge, W. G. (2015). Argon diffusion in Apollo 16 impact glass spherules: Implications for ${ }^{40} \mathrm{Ar} /{ }^{39} \mathrm{Ar}$ dating of lunar impact events. Geochimica et Cosmochimica Acta, 148, 251-268. https://doi. org/10.1016/j.gca.2014.09.031

Grieve, R. A., \& Pesonen, L. J. (1996). Terrestrial impact craters: their spatial and temporal distribution and impacting bodies. In Worlds in Interaction: Small Bodies and Planets of the Solar System, (pp. 357-376). Dordrecht: Springer.

Hidaka, H., Ebihara, M., \& Yoneda, S. (2000). Neutron capture effects on samarium, europium, and gadolinium in Apollo 15 deep drill-core samples. Meteoritics \& Planetary Science, 35(3), 581-589. https://doi.org/10.1111/j.1945-5100.2000.tb01438.x

Huang, Y. H., Minton, D. A., Zellner, N. E., Hirabayashi, M., Richardson, J. E., \& Fassett, C. I. (2018). No change in the recent lunar impact flux required based on modeling of impact glass spherule age distributions. Geophysical Research Letters, 45(14), 6805-6813. https://doi. org/10.1029/2018gl077254

Hui, S. S. M. (2011). Microanalysis of impactors of the earth and impact products from the Moon: the origin and evolution of micrometeorites, and tracking bombardment history through chemical and radioisotopic memories of lunar impact spherules. Ph. D. dissertation. The Australian National University. http://hdl.handle.net/1885/148242

Ivanov, B. A., Neukum, G., Bottke, W. F., \& Hartmann, W. K. (2002). The comparison of size-frequency distributions of impact craters and asteroids and the planetary cratering rate. Asteroids III, 1, 89-101.

Johnson, B. C., \& Melosh, H. J. (2012). Formation of spherules in impact produced vapor plumes. Icarus, 217(1), 416-430. https://doi.org/ 10.1016/j.icarus.2011.11.020

Jourdan, F. (2012). The ${ }^{40} \mathrm{Ar} /{ }^{39} \mathrm{Ar}$ dating technique applied to planetary sciences and terrestrial impacts. Australian Journal of Earth Sciences, 59(2), 199-224. https://doi.org/10.1080/08120099.2012.644404

Jourdan, F., Reimold, W. U., \& Deutsch, A. (2012). Dating terrestrial impact structures. Elements, 8(1), 49-53. https://doi.org/10.2113/ gselements.8.1.49

Jourdan, F., Timms, N. E., Eroglu, E., Mayers, C., Frew, A., Bland, P. A., et al. (2017). Collisional history of asteroid Itokawa. Geology, 45(9), 819-822. https://doi.org/10.1130/g39138.1

Kirchoff, M. R., Chapman, C. R., Marchi, S., Curtis, K. M., Enke, B., \& Bottke, W. F. (2013). Ages of large lunar impact craters and implications for bombardment during the Moon's middle age. Icarus, 225(1), 325-341. https://doi.org/10.1016/j.icarus.2013.03.018

Korotev, R. L. (1997). Some things we can infer about the Moon from the composition of the Apollo 16 regolith. Meteoritics \& Planetary Science, 32(4), 447-478. https://doi.org/10.1111/j.1945-5100.1997.tb01291.x

Korotev, R. L., Zeigler, R. A., \& Floss, C. (2010). On the origin of impact glass in the Apollo 16 regolith. Geochimica et Cosmochimica Acta, 74(24), 7362-7388. https://doi.org/10.1016/j.gca.2010.09.020

Levine, J., Becker, T. A., Muller, R. A., \& Renne, P. R. (2005). ${ }^{40} \mathrm{Ar} /{ }^{39} \mathrm{Ar}$ dating of Apollo 12 impact spherules. Geophysical Research Letters, 32(15), L15201. https://doi.org/10.1029/2005gl022874

Levine, J., Renne, P. R., \& Muller, R. A. (2007). Solar and cosmogenic argon in dated lunar impact spherules. Geochimica et Cosmochimica Acta, 71(6), 1624-1635. https://doi.org/10.1016/j.gca.2006.11.034

Lucey, P. G., \& Hawke, B. R. (1988). A remote mineralogic perspective on gabbroic units in the lunar highlands. In Lunar and Planetary Science Conference Proceedings, (Vol. 18, pp. 355-363).

Mazrouei, S., Ghent, R. R., Bottke, W. F., Parker, A. H., \& Gernon, T. M. (2019). Earth and Moon impact flux increased at the end of the Paleozoic. Science, 363(6424), 253-257. https://doi.org/10.1126/science.aar4058

McKay, D. S., Heiken, G., Basu, A., Blanford, G., Simon, S., Reedy, R., et al. (1991). The lunar regolith. Lunar Sourcebook, $285-356$.

Melosh, H. J., \& Vickery, A. M. (1991). Melt droplet formation in energetic impact events. Nature, 350(6318), 494. https://doi.org/10.1038/ $350494 \mathrm{a} 0$

Morris, R. V. (1978). The surface exposure/maturity/of lunar soils-Some concepts and $\mathrm{I}_{\mathrm{s}} / \mathrm{FeO}$ compilation. In Lunar and Planetary Science Conference Proceedings, (Vol. 9, pp. 2287-2297).

Morris, R. V., See, T. H., \& Hörz, F. (1986). Composition of the Cayley Formation at Apollo 16 as inferred from impact melt splashes. Journal of Geophysical Research - Solid Earth, 91(B13). https://doi.org/10.1029/jb091ib13p00e21

Nemchin, A. A., Norman, M. D., Zeigler, R. A., \& Grange, M. L. (2013). Constraining the flux of impactors postdating the heavy bombardment using U-Pb ages of impact glasses. In 44th Lunar and Planetary Science Conference, Abstract \#1834. Houston: The Lunar and Planetary Institute. http://www.lpi.usra.edu/meetings/lpsc2013/pdf/1834.pdf

Nguyen, P., \& Zellner, N. (2019). Using size and composition to assess the quality of lunar impact glass ages. Geosciences, 9(2), 85. https:// doi.org/10.3390/geosciences9020085

Norman, M. D. (2005). Lunar impact breccias: petrology, crater setting, and bombardment history of the Moon. Australian Journal of Earth Sciences, 52(4-5), 711-723. https://doi.org/10.1080/08120090500170443

Norman, M. D., Adena, K. J. D., \& Christy, A. G. (2012). Provenance and Pb isotopic ages of lunar volcanic and impact glasses from the Apollo 17 landing site. Australian Journal of Earth Sciences, 59(2), 291-306. https://doi.org/10.1080/08120099.2011.615471

Norman, M. D., Ireland, T. R., \& Cousins, L. (2014). U-Pb ages and chemical compositions of Apollo 11 regolith glasses. In 45th Lunar and Planetary Science Conference (2014), Abstract \#1756. Houston: The Lunar and Planetary Institute. http://www.lpi.usra.edu/meetings/ lpsc2014/pdf/1756.pdf

Norman, M.D., Jourdan, F., Hui, S., 2019. Petrography, major and trace element compositions, and Ar isotopic ages for 30 impact glasses from Apollo 16 regolith 66031. Interdisciplinary Earth Data Alliance (IEDA). https://doi.org/10.1594/IEDA/111339. .

Pepin, R. O., Basford, J. R., Dragon, J. C., Coscio, M. R. Jr., \& Murthy, V. R. (1974). Rare gases and trace elements in Apollo 15 drill core fines Depositional chronologies and K-Ar ages, and production rates of spallation-produced He-3, Ne-21, and Ar-38 versus depth. In Lunar and Planetary Science Conference Proceedings, (Vol. 5, pp. 2149-2184).

Pepin, R. O., Dragon, J. C., Johnson, N. L., Bates, A., Coscio, M. R. Jr., \& Murthy, V. R. (1975). Rare gases and Ca, Sr, and Ba in Apollo 17 drill-core fines. In Lunar and Planetary Science Conference Proceedings, (Vol. 6, pp. 2027-2055). 
Prettyman, T. H., Hagerty, J. J., Elphic, R. C., Feldman, W. C., Lawrence, D. J., McKinney, G. W., \& Vaniman, D. T. (2006). Elemental composition of the lunar surface: Analysis of gamma ray spectroscopy data from Lunar Prospector. Journal of Geophysical Research, Planets, 111(E12). https://doi.org/10.1029/2005je002656

Reedy, R. C., Arnold, J. R., \& Lal, D. (1983). Cosmic-ray record in solar system matter. Science, 219(4581), 127-135. https://doi.org/10.1126/ science.219.4581.127

Reid, A. M., Warner, J., Ridley, W. I., Johnston, D. A., Harmon, R. S., Jakes, P., \& Brown, R. W. (1972). The major element compositions of lunar rocks as inferred from glass compositions in the lunar soils. In Lunar and Planetary Science Conference Proceedings, (Vol. 3, p. 363378).

Ryder, G., Norman, M. D., \& Taylor, G. J. (1997). The complex stratigraphy of the highland crust in the Serenitatis region of the Moon inferred from mineral fragment chemistry. Geochimica et Cosmochimica Acta, 61(5), 1083-1105. https://doi.org/10.1016/s0016-7037(96) 00386-9

See, T. H., Hörz, F., \& Morris, R. V. (1986). Apollo 16 impact-melt splashes: Petrography and major-element composition. Journal of Geophysical Research - Solid Earth, 91(B13), E3-E20. https://doi.org/10.1029/jb091ib13p000e3

Shuster, D. L., \& Cassata, W. S. (2015). Paleotemperatures at the lunar surfaces from open system behavior of cosmogenic ${ }^{38} \mathrm{Ar}$ and radiogenic ${ }^{40}$ Ar. Geochimica et Cosmochimica Acta, 155, 154-171. https://doi.org/10.1016/j.gca.2015.01.037

Spudis, P. D., Hawke, B. R., \& Lucey, P. G. (1988). Materials and formation of the Imbrium basin. In Lunar and Planetary Science Conference Proceedings, (Vol. 18, pp. 155-168).

Swindle, T. D., Kring, D. A., \& Weirich, J. R. (2014). 40Ar/39Ar ages of impacts involving ordinary chondrite meteorites. Geological Society, London, Special Publications, 378(1), 333-347. https://doi.org/10.1144/sp378.6

Taylor, G. J., Warren, P., Ryder, G., Delano, J., Pieters, C., \& Lofgren, G. (1991). Lunar rocks. Lunar sourcebook, 183-284.

Tera, F., Papanastassiou, D. A., \& Wasserburg, G. J. (1974). Isotopic evidence for a terminal lunar cataclysm. Earth and Planetary Science Letters, 22(1), 1-21. https://doi.org/10.1016/0012-821x(74)90059-4

Tera, F., \& Wasserburg, G. J. (1974). U-Th-Pb systematics on lunar rocks and inferences about lunar evolution and the age of the moon. In Lunar and Planetary Science Conference Proceedings, (Vol. 5, pp. 1571-1599).

Warren, P. H. (1994). Lunar and martian meteorite delivery services. Icarus, 111(2), 338-363. https://doi.org/10.1006/icar.1994.1149

Wetherill, G. W. (1975). Late heavy bombardment of the moon and terrestrial planets. In Lunar and Planetary Science Conference Proceedings, (Vol. 6, pp. 1539-1561)

Wetherill, G. W. (1977). Evolution of the Earth's planetesimal swarm subsequent to the formation of the Earth and Moon. In Lunar and Planetary Science Conference Proceedings, (Vol. 8, pp. 1-16).

Wünnemann, K., Collins, G. S., \& Osinski, G. R. (2008). Numerical modelling of impact melt production in porous rocks. Earth and Planetary Science Letters, 269(3-4), 530-539. https://doi.org/10.1016/j.epsl.2008.03.007

Zeigler, R. A., Korotev, R. L., Jolliff, B. L., Haskin, L. A., \& Floss, C. (2006). The geochemistry and provenance of Apollo 16 mafic glasses. Geochimica et Cosmochimica Acta, 70(24), 6050-6067. https://doi.org/10.1016/j.gca.2006.08.040

Zellner, N. E. (2017). Cataclysm no more: new views on the timing and delivery of lunar impactors. Origins of Life and Evolution of Biospheres, 47(3), 261-280. https://doi.org/10.1007/s11084-017-9536-3

Zellner, N. E. B., \& Delano, J. W. (2015). 40Ar/39Ar ages of lunar impact glasses: Relationships among Ar diffusivity, chemical composition, shape, and size. Geochimica et Cosmochimica Acta, 161, 203-218. https://doi.org/10.1016/j.gca.2015.04.013

Zellner, N. E. B., Delano, J. W., Swindle, T. D., Barra, F., Olsen, E., \& Whittet, D. C. B. (2009a). Apollo 17 regolith, $71501,262:$ a record of impact events and mare volcanism in lunar glasses. Meteoritics \& Planetary Science, 44(6), 839-851. https://doi.org/10.1111/j.19455100.2009.tb00772.x

Zellner, N. E. B., Delano, J. W., Swindle, T. D., Barra, F., Olsen, E., \& Whittet, D. C. B. (2009b). Evidence from ${ }^{40} \mathrm{Ar} /{ }^{39} \mathrm{Ar}$ ages of lunar impact glasses for an increase in the impact rate $~ 800$ Ma ago. Geochimica et Cosmochimica Acta, 73(15), 4590-4597. https://doi.org/ 10.1016/j.gca.2009.04.027

Zellner, N. E. B., Norman, M. D., \& Jourdan, F. (2013). Compositions and ages of Apollo 15 lunar impact and volcanic glasses: next results. $44^{\text {th }}$ Lunar and Planetary Science Conf., Abstract \#2539. Houston: The Lunar and Planetary Institute. http://www.lpi.usra.edu/meetings/ lpsc2013/pdf/2539.pdf

Zellner, N. E. B., Spudis, P. D., Delano, J. W., \& Whittet, D. C. B. (2002). Impact glasses from the Apollo 14 landing site and implications for regional geology. Journal of Geophysical Research, Planets, 107(E11). https://doi.org/10.1029/2001je001800 